\title{
Study and Analysis of Certain Parameters in BRICS Countries
}

\author{
Dr. Putta Madhavi \\ Assistant Professor (Economics), Department of Women's Studies, \\ Sri Padmavati Mahila Visvavidyalayam (Women's University), Tirupati - 517 502, AP, India
}

\begin{abstract}
This paper is about the gender gap among the BRICS countries during last one decade. Originally Brazil, Russia, India and China were grouped in 2001 by Jim O'Neil and officially became a diplomaticpolitical entity called BRIC in the year 2006. Later in the year 2011, South Africa joined in the group and renamed as BRICS. The emerging economy of these countries is to forecast to realize real and fast economic growth of the region. This group countries collective contribution to world GDP has increased from $11 \%$ in 1990 to 25\% in 2011. The BRICS are good example for the present study because of two reasons; one, the repaid growth of economies and the second, the high proportionate (42\%) of world's higher education. It is to be noted that the last few years in the BRICS countries, the gender gap reports shown both positive and negative sign in some of the key areas. The gender gap score for the various parameters viz., economic participation, education, health and political empowerment among the BRICS countries are compared and a brief analysis of the reports are listed highlighting the status of India the in the group.
\end{abstract}

Keywords: BRICS, Gender Gap Index, Economic Participation, Educational Attainment, Health, Political Empowerment

\section{INTRODUCTION}

Originally Brazil, Russia, India and China were grouped as BRICs in 2001 by Jim O'Neil and this group officially became a diplomatic-political entity called BRIC in the year 2006. Later in the year 2011, South Africa joined in the group and called the group as BRICS. The emerging economy of these countries is to forecast to realize real and fast economic growth of the region. The aim of the BRICS is that the growth of these countries should be larger than some of the developed countries' economies. This group countries collective contribution to world GDP has increased from $11 \%$ in 1990 to $25 \%$ in 2011 . This paper is about certain parameters based on gender gap indexes to study the status in the emerging power countries of the world with special reference to BRICS. Such study provides a measure of the extent of gender equality in terms of their efficient utilization of human capital and for enhancing its economic growth. The study on gender gap also point to the empowerment of women and competitiveness among countries. It has also been argued that countries that discriminate against female could potentially lose out on the skills and expertise of female. The BRICS is a good example for the present study because of two reasons; one, the repaid growth of economies and the second, the high proportionate (42\%) of world's higher education. The economic change in BRICS and their incorporation in to the world's economy will made a positive sign in the change of female status in certain aspects especially in India.

According to the World Banks classification of countries, South Africa, Brazil and China are deemed upper middle income countries, with Russia classified as a high income country and India as a lower middle income country (World Bank, 2012). The growth potential of the BRICS countries has been widely acknowledged and Goldman Sachs economists predicted that the BRIC economies (Brazil, Russia, India and China) would outperform that of the G7 countries (the richest countries) before the middle of the century (Glosny, 2010). A distinguishing feature of all BRICS countries is fast-developing, emerging economies and newly industrialized countries. Being members of the G-20 group of countries, BRICS countries boast enormous political clout in their respective regions and in the international arena. A crucial factor is that all BRICS countries hold important stocks of resources and effective utilization of these resources amounts to a positive spinoff for each individual country (Arkhangelskaya, 2011).

Globally the proportion of women joining the hands in various aspects, such as economic development, higher education acquirements, political empowerment, falling fertility which have transformed female participation rates over the past few years. Rising educational acquirements among women have pushed them to enter the world of work. Over the past two/three decades, there is reasonably increase in women joining the job sector resulting in the gender participation gap being narrowed. Gender inequality in education and employment reduces economic growth and the same is expressed by many researchers. It has been found that women's employment and earnings benefit their bargaining power in the home, which in turn has positive spinoffs on savings, and promotes better investment in children's health and their education which ultimately 
benefit economic growth (Klasen \& Lamanna, 2009).The gender gap index in the BRICS countries is discussed in the areas of economy, education, health and empowerment.

\section{GENDER RATIO AT DIFFERENT STAGES OF LIFE}

The Male-to-Female ratio at the various stages of life in the BRICS countries is listed in the Table 1. The gender ratio at all the stages is almost same in India and China. Male to Female ratio of total population is less than one in Brazil, Russia and South Africa indicating more female population than male. But in China and India, the ratio is more than one indicates that the male population is dominating female. It can be observed from the data that the male-to-female ratio in Russia in 0.44 in the stage 65 years and above and this is because of more life expectancy of female than male in Russia when compared to other BRICS countries.

Table1: Male-to-Female Ratio in BRICS

\begin{tabular}{|l|l|l|l|l|l|l|}
\hline S.No. & Stage & Brazil $^{\text {\# }}$ & Russia $^{\text {\$ }}$ & India $^{\text {}}$ & China & South Africa \\
\hline 1 & At birth & 1.05 & 1.06 & 1.12 & 1.11 & 1.02 \\
2 & 0-14 years & 1.04 & 1.06 & 1.13 & 1.16 & 1.01 \\
3 & 15-24 years & 1.03 & 1.05 & 1.13 & 1.13 & 1.01 \\
4 & 25-54 years & 0.98 & 0.96 & 1.06 & 1.05 & 1.07 \\
5 & 55-64 years & 0.89 & 0.86 & 1.08 & 1.06 & 0.98 \\
6 & 65 \& above & 0.74 & 0.44 & 0.91 & 0.92 & 0.67 \\
\hline $\mathbf{7}$ & Total Population & $\mathbf{0 . 9 7}$ & $\mathbf{0 . 8 6}$ & $\mathbf{1 . 0 8}$ & $\mathbf{1 . 0 6}$ & $\mathbf{0 . 9 9}$ \\
\hline
\end{tabular}

\section{GENDER GAP INDEX}

The statistics of Gender Gap Index in various countries of the world are published by World Economic Forum. The details pertaining to the BRICS countries are extracted from these data. Ten years of measuring the gender gap in BRICS countries helps to know the status of female and the study in the four aspects i.e., in economic participation \& opportunity, education, health and political empowerment areas and is given in Tables 2, 3, 4 and 5 respectively and also shown in Figures 1, 2, 3, and 4 respectively. The score given in the tables is based on 1.00 for equality and 0.00 for inequality. Tables displays gender gap indexes between males and females and do not reflect actual levels.

The gender gap scores for economic participation and opportunity in the last ten years (Table 2) indicate that the status of female in economic participation and opportunity is very poor in India compared to other BRICS countries and is at the decreasing rate. The Figure 1 clearly depicts that the female in Russia are in better position compared to other BRICS and Brazil, China and South Africa are almost with the same index but far better than India.

Table 2: The Gender Gap Scores for Economic Participation and Opportunity

\begin{tabular}{|l|l|l|l|l|l|l|}
\hline S.No. & Year & Brazil & Russia & India & China & South Africa \\
\hline 1 & 2015 & 0.642 & 0.731 & 0.383 & 0.657 & 0.670 \\
2 & 2014 & 0.649 & 0.726 & 0.410 & 0.656 & 0.647 \\
3 & 2013 & 0.656 & 0.720 & 0.446 & 0.675 & 0.651 \\
4 & 2012 & 0.650 & 0.720 & 0.459 & 0.675 & 0.659 \\
5 & 2011 & 0.649 & 0.737 & 0.396 & 0.683 & 0.665 \\
6 & 2010 & 0.643 & 0.736 & 0.403 & 0.693 & 0.673 \\
7 & 2009 & 0.637 & 0.740 & 0.412 & 0.696 & 0.663 \\
8 & 2008 & 0.653 & 0.743 & 0.399 & 0.692 & 0.568 \\
9 & 2007 & 0.645 & 0.735 & 0.398 & 0.648 & 0.586 \\
10 & 2006 & 0.604 & 0.696 & 0.397 & 0.621 & 0.556 \\
\hline 2006-2015 Change & $\mathbf{\Delta 0 . 0 3 8}$ & $\mathbf{0 . 0 3 4}$ & $\mathbf{\nabla - 0 . 0 1 3}$ & $\mathbf{\Delta 0 . 0 3 7}$ & $\mathbf{\Delta 0 . 1 1 4}$ \\
\hline
\end{tabular}

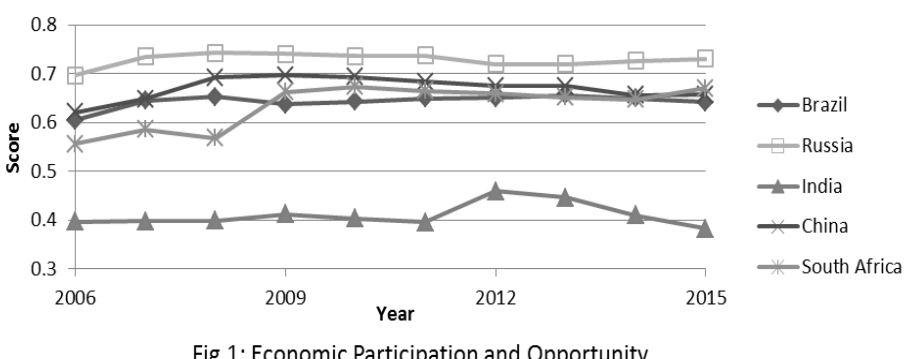

Fig.1: Economic Participation and Opportunity 
Study and Analysis of Certain Parameters in BRICS Countries

The scores for Educational attainment given in Table 3 reveals that the scores are almost equal to 1.0 in Brazil, Russia, China and South Africa indicating the female and male are equally educated and there is little decrease in the index rate for South Africa compared to all the other countries in the group. The India has significantly improved by $7.7 \%$ in the area of education and the reason for the improvement is due to Government policies encouraging and providing the education to the female, but still a long way to go to reach the female on par with male in educational attainment as in the case of other BRICS and it can be seen clearly in the Figure 2.

Table 3: The Gender Gap Scores for Educational Attainment

\begin{tabular}{|l|l|l|l|l|l|l|}
\hline S.No. & Year & Brazil & Russia & India & China & South Africa \\
\hline 1 & 2015 & 1.000 & 1.000 & 0.896 & 0.988 & 0.987 \\
2 & 2014 & 1.000 & 1.000 & 0.850 & 0.986 & 0.987 \\
3 & 2013 & 1.000 & 0.998 & 0.857 & 0.988 & 0.994 \\
4 & 2012 & 1.000 & 0.998 & 0.852 & 0.982 & 0.980 \\
5 & 2011 & 0.990 & 0.998 & 0.837 & 0.981 & 0.981 \\
6 & 2010 & 0.990 & 0.999 & 0.837 & 0.981 & 0.996 \\
7 & 2009 & 0.999 & 0.999 & 0.843 & 0.980 & 0.996 \\
8 & 2008 & 1.000 & 0.999 & 0.845 & 0.978 & 0.996 \\
9 & 2007 & 0.969 & 0.999 & 0.819 & 0.957 & 0.991 \\
10 & 2006 & 0.972 & 0.999 & 0.819 & 0.957 & 0.993 \\
\hline \multicolumn{2}{|l|}{$\mathbf{0 0 0 6 - 2 0 1 5}$ Change } & $\mathbf{\Delta 0 . 0 2 8}$ & $\mathbf{\Delta 0 . 0 0 1}$ & $\mathbf{\Delta 0 . 0 7 7}$ & $\mathbf{\Delta 0 . 0 3 1}$ & $\mathbf{\nabla - 0 . 0 0 6}$ \\
\hline
\end{tabular}

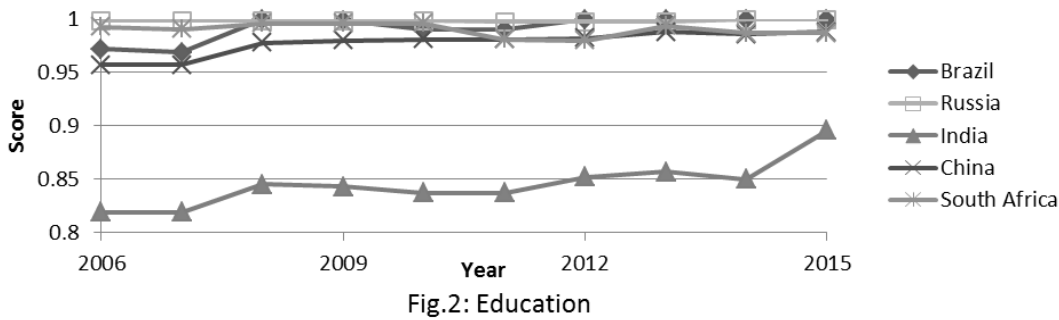

The gender gap scores for health are shown in the Table 4 and also represented in the form of Figure 3. The indexes for the health are almost same in Brazil, Russia and South Africa and close to 1.0 indicated the health consciousness among female and male is very good and maintaining with same level. Though the indexes for India and China are around $0.93-0.94$, but the change in the last ten years shows that there is slightly negligence in the health care of female compared to male.

Based on the scores given in Table 5 and Figure 4, the scores are less than 0.5 in case of political empowerment in all BRICS countries and reveals that there is more male domination in political area. Only South Africa and India fared well with regard to the gender gap score for political empowerment. The gender gap score for political empowerment in India is increasing compared to all countries in BRICS and is very low in Russia speaks the poor representation of female in political empowerment. The score is almost doubled in the last ten years in India (from 0.227 to 0.433 ) and is good sign that the female are taking acting role in the political area.

Table 4: The Gender Gap Scores for Health

\begin{tabular}{|l|l|l|l|l|l|l|}
\hline S.No. & Year & Brazil & Russia & India & China & South Africa \\
\hline 1 & 2015 & 0.980 & 0.979 & 0.942 & 0.919 & 0.980 \\
2 & 2014 & 0.980 & 0.979 & 0.937 & 0.940 & 0.980 \\
3 & 2013 & 0.980 & 0.979 & 0.931 & 0.940 & 0.968 \\
4 & 2012 & 0.980 & 0.979 & 0.931 & 0.934 & 0.968 \\
5 & 2011 & 0.980 & 0.979 & 0.931 & 0.933 & 0.968 \\
6 & 2010 & 0.980 & 0.979 & 0.931 & 0.929 & 0.968 \\
7 & 2009 & 0.980 & 0.979 & 0.931 & 0.947 & 0.975 \\
8 & 2008 & 0.980 & 0.979 & 0.931 & 0.941 & 0.975 \\
9 & 2007 & 0.980 & 0.979 & 0.931 & 0.941 & 0.975 \\
10 & 2006 & 0.980 & 0.979 & 0.962 & 0.936 & 0.976 \\
\hline 2006-2015 Change & $\mathbf{\Delta 0 . 0 0 0}$ & $\mathbf{\Delta ~ 0 . 0 0 0}$ & $\mathbf{\nabla - 0 . 0 2 0}$ & $\mathbf{\nabla - 0 . 0 1 7}$ & $\mathbf{\Delta 0 . 0 0 4}$ \\
\hline
\end{tabular}

Source: World Economic Forum 2015 


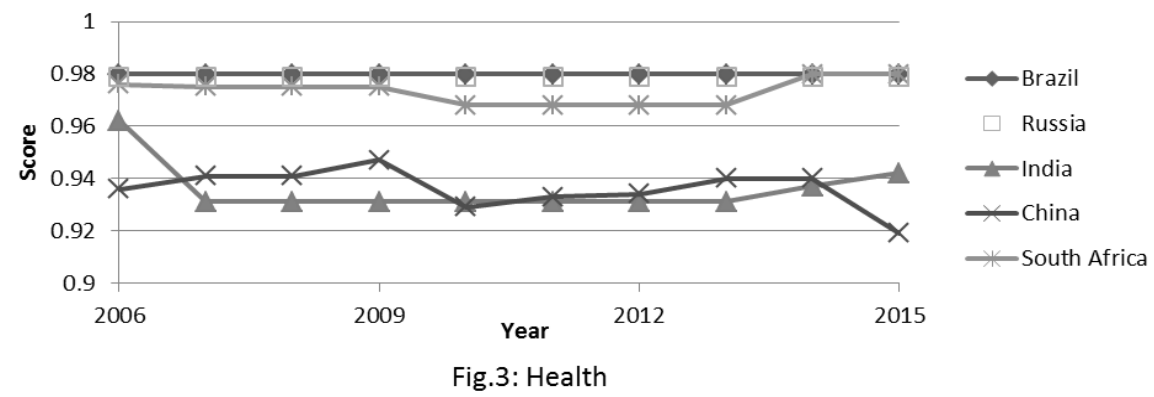

Table 5: The Gender Gap Scores for Political Empowerment

\begin{tabular}{|l|l|l|l|l|l|l|}
\hline S.No. & Year & Brazil & Russia & India & China & South Africa \\
\hline 1 & 2015 & 0.123 & 0.066 & 0.433 & 0.162 & 0.400 \\
2 & 2014 & 0.148 & 0.066 & 0.385 & 0.151 & 0.397 \\
3 & 2013 & 0.144 & 0.095 & 0.385 & 0.160 & 0.392 \\
4 & 2012 & 0.134 & 0.095 & 0.334 & 0.150 & 0.392 \\
5 & 2011 & 0.053 & 0.100 & 0.312 & 0.150 & 0.377 \\
6 & 2010 & 0.049 & 0.100 & 0.291 & 0.150 & 0.377 \\
7 & 2009 & 0.063 & 0.076 & 0.273 & 0.141 & 0.449 \\
8 & 2008 & 0.063 & 0.076 & 0.248 & 0.141 & 0.353 \\
9 & 2007 & 0.062 & 0.034 & 0.227 & 0.111 & 0.260 \\
10 & 2006 & 0.061 & 0.034 & 0.227 & 0.111 & 0.326 \\
\hline 2006-2015 Change & $\mathbf{\Delta 0 . 0 6 2}$ & $\mathbf{\Delta 0 . 0 3 2}$ & $\mathbf{\Delta 0 . 2 0 6}$ & $\mathbf{\Delta 0 . 0 5 1}$ & $\mathbf{\Delta 0 . 0 7 4}$ \\
\hline
\end{tabular}

Source: World Economic Forum 2015

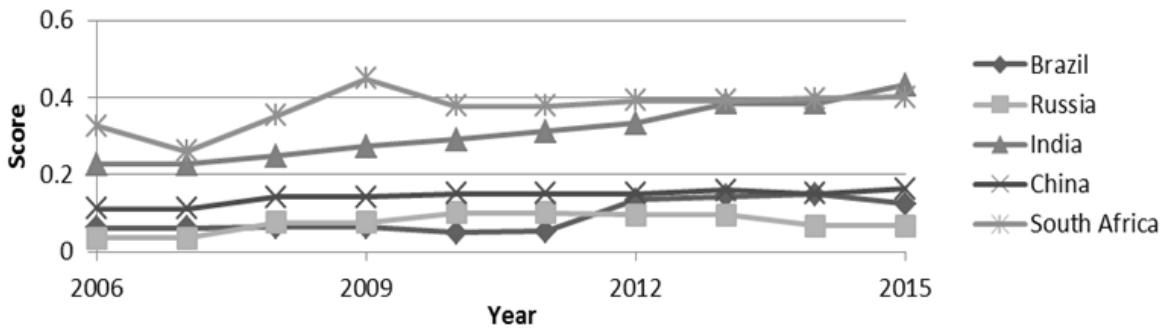

Fig.4: Political Empowerment

\section{CONCLUSIONS}

The main aim of the paper is to study with regard to the status of female in Economic Participation and Opportunity, Education Attainment, Health and Political Empowerment in the BRICS countries. The study is based on the gender gap indexes published in the World Economic Forum 2015. Based on the statistics about Gender Equality from the World Bank data, it is to state that the Male to Female ratio of total population is less than one in Brazil, Russia and South Africa indicating more female population than male, but in China and India, the ratio is more than one. The gender gap index scores indicate the status of female in economic participation and opportunity is very poor in India compared to other BRICS countries and is at the decreasing rate. The scores are almost equal to 1.0 in Brazil, Russia, China and South Africa indicating the female and male are equally educated but still a long way to go to reach the female on par with male in educational attainment in India. The indexes for the health are almost same in Brazil, Russia and South Africa and close to 1.0 indicated the health consciousness among female and male is very good compared to India and China. The score for political empowerment in India is increasing compared to all countries in BRICS and is almost doubled in the last ten years in India, a good sign that the female are participating actively in the political area.

\section{REFERENCES}

[1]. Glosny, M.A., (2010), 'China and the BRICS: A real (but limited) partnership in a unipolar world,' Polity, 42.

[2]. Jensen, R.T., (2010), 'Economic Opportunities and Gender Differences in Human Capital: Experimental Evidence for India', National Bureau of Economic Research.

[3]. Duflo, E, (2011), 'Women's employment and economic development', National Bureau of Economic Research.http://www.nber.org/papers/w17702.

[4]. World Bank, (2012), World Development Report 2012: Gender Equality and Development. http://data.worldbank.org/topic. 
[5]. http://www.imf.org/external/pubs/ft/weo/2013/01/weodata/weorept.aspx

[6]. BRICS - Joint Statistical Publication (2014), published by Instituto Brasileiro De Geografia E Estatistica - IBGE, Brasil (ISBN 978-85-240-4318-5), 2014. http://www.bricsforum.org

[7]. http://www3.weforum.org/docs/GGGR2015/cover.pdf, World Economic Forum - The Global Gender Gap Report 2015.

[8]. World Economic Forum: The Global Gender Gap Report 2015, http://reports.weforum.org/global-gender-gap-report2015.

[9]. Madhavi, P (2016), "Status of Female in BRICS - A Changing Scenario", Proceedings of 3 days International Conferencce on Multilateral Cooperation: Emerging Global Scenario, organized by UGC Center for Southeast Asian and Pacific Studies, Sri Venkateswara University, Tirupati. 